\title{
Efficient Utilization of Plant Resources by Alkaline Extraction
}

Sakagami $\mathrm{H}^{1 *}$, Ohkoshi $\mathrm{E}^{1}$, Amano $\mathrm{S}^{1}$, Satoh $\mathrm{K}^{1,2}$, Kanamoto $\mathrm{T}^{4}$, Terakubo $\mathrm{S}^{4}$, Nakashima $\mathrm{H}^{4}$, Sunaga $\mathrm{K}^{5}$, Otsuki $\mathrm{T}^{6}$, Ikeda $\mathrm{H}^{7}$ and Fukuda $\mathrm{T}^{7}$

${ }^{1}$ Meikai University School of Dentistry, Sakado, Saitama, Japan

${ }^{2}$ School of Medicine, Showa University, Tokyo, Japan

${ }^{3}$ Matsuyama University School of Pharmacy, Matsuyama, Japan

${ }^{4}$ St. Marianna University School of Medicine, Kanagawa, Japan

${ }^{5}$ Faculty of Pharmaceutical Sciences, Josai University, Sakado, Saitama, Japan

${ }^{6}$ Taisho Pharmaceutical Co., Ltd., Tokyo, Japan

${ }^{7}$ Satoen Food and Drug Laboratories, Satoen Co., Ltd., Shizuoka, Japan

\begin{abstract}
As compared to the studies with hot water extracts of plants, those with alkaline extracts were limited. Both alkaline and hot water extracts from green tea leaf, oolong tea leaf and orange flower were compared for their biological activities. Plant materials were successively extracted first with hot-water and then alkaline solution, or extracted directly with alkaline solution. Viable cell number of HIV-infected and UV-irradiated cells was determined by MTT method. Antibacterial activity against Porphyromonas gingivalis 381 was determined by turbidity assay. Cytochrome P-450 (CYP)3A4 activity was measured by $\beta$-hydroxylation of testosterone using human recombinant CYP3A4 (Figure 5). Radical intensity of superoxide and hydroxyl radical was determined by ESR spectroscopy. Alkaline extraction recovered twice as much as dried materials as compared with water extraction. Water extracts showed higher anti-bacterial, CYP3A4 inhibitory and superoxide scavenging activities, whereas alkaline extract showed higher anti-HIV and hydroxyl radical scavenging activity. Both water and alkaline extracts showed comparable anti-UV activity. The present study suggests the usefulness of alkaline extraction for the efficient utilization of the natural resources.
\end{abstract}

Keywords: Alkaline extraction; Hot-water extraction; Anti-HIV activity; Anti-UV activity; Anti-bacterial activity; CYP3A4 inhibition; Radical scavenging activity

\section{Introduction}

We have previously reported that lignin-carbohydrate complex (LCC) fractions prepared by acid precipitation of the alkaline extracts of pine cone, pine seed shell, catuaba bark, cacao husk, cacao mass, Lentinus edodes mycelia potently protected the cells from HIVinfection [selectivity index (SI)=7 311] [1], and from UV irradiation (SI=7.6 >38.1) [2]. Similarly, crude alkaline extract of the leaves of Sasa senanensis Rehder (SE) showed comparable anti-HIV (SI=36-45) and anti-UV activity (SI=20 39) with LCC fractions [3]. On the other hand, hot-water extracts of a total of 35 Kampo medicines and their constituent plants had much lower anti-HIV $(\mathrm{SI}=1 \sim 8)$ and anti-UV activity (SI=1 4.4) [4]. This raised a possibility that the use of alkaline extraction is more advantageous than hot-water extraction to obtain higher amounts of anti-HIV and anti-UV substances. However, this possibility has not yet been tested with water and alkaline extracts prepared from the same plant species. To clarify this point, we prepared hot-water extract (Fr. I), alkaline extract of its residue (Fr. II), and total alkaline extract (Fr. III) from green tea leaf (GT), oolong tea leaf (OT) and orange flower (OF) (Figure 1), and compared their anti-HIV, antiUV, anti-bacterial, cytochrome P-450 (CYP)3A4 inhibitory and radical scavenging activities, together with their compositional analysis with HPLC.

\section{Materials and Methods}

\section{Materials}

The following chemicals and reagents were obtained from the indicated companies: Dulbecco's modified Eagle's medium (DMEM): Gibco BRL, Grand Island, NY, USA; fetal bovine serum (FBS), 3-(4,5-dimethylthiazol-2-yl)-2,5-diphenyltetrazolium bromide (MTT), hypoxanthine (HX), xanthine oxidase (XOD), diethylenetriaminepentaacetic acid (DETAPAC), 5,5-dimethyl-1-pyrroline-N-oxide (DMPO)
(Dojin, Kumamoto, Japan), RPMI-1640 medium, azidothymidine (AZT), 2',3'-dideoxycytidine (ddC), gallic acid (Sigma-Aldrich Co. St. Louis, MO, USA), dimethyl sulfoxide (DMSO), caffeine, hesperidin, dextran sulfate $(5 \mathrm{kDa})$ (Wako Pure Chemical Ind., Ltd., Osaka, Japan), sodium ascorbate (Tokyo Chemical Industry Co., Ltd., Tokyo, Japan), (-)-epigallocatechin (EGC), (-)-epigallocatechin gallate (EGCg), (-)-epicatechin gallate (ECg) (Nagara Science Co., Ltd., Gifu, Japan), curdlan sulphate: $79 \mathrm{kDa}$ (Ajinomoto Co. Inc., Tokyo, Japan).

\section{Preparation of water and alkaline extracts}

Five g green tea leaf (GT) (Kimpo, Satoen Co. Ltd., Shizuoka, Japan), oolong tea leaf (OT) (Mitsui Norin Co. Ltd., Tokyo, Japan) or orange flower (OF) (Tochimoto Tenkaido Co.,Ltd., Osaka, Japan) were extracted at $80^{\circ} \mathrm{C}$ for $30 \mathrm{~min}$ with $100 \mathrm{ml}$ of water, and filtered through filter paper (No. 5A, Kiriyama glass Co., Tokyo, Japan) (Figure 1). The filtrate was concentrated and lyophilized to give the water extract (Fr. I: GT-I, OT-I, OF-I) at the yield of $19.3,15.6$ and $45.2 \%$, respectively. The residue was extracted at $80^{\circ} \mathrm{C}$ for $30 \mathrm{~min}$ with $100 \mathrm{ml}$ of $0.15 \mathrm{M} \mathrm{NaOH}$ and filtered. The filtrate was neutralized with $\mathrm{HCl}$, concentrated and lyophilized to give the alkaline extract of the residue (Fr. II: GT-II, OTII, OF-II) at the yield of 34.0, 30.0 and $19.0 \%$, respectively $(18.1,18.1$, $9.7 \%$, respectively, after correction for $\mathrm{NaCl}$ present in the extracts). Alternatively, GT, OT or OF (3 g) were directly extracted with $100 \mathrm{ml}$

*Corresponding author: Hirosih Sakagami, Division of Pharmacology, Meikai University School of Dentistry, Sakado, Saitama 350-0283, Japan, Tel: +81 492792758; Fax: +81 492855171; E-mail: sakagami@dent.meikai.ac.jp

Received July 12, 2013; Accepted August 01, 2013; Published August 03, 2013

Citation: Sakagami H, Ohkoshi E, Amano S, Satoh K, Kanamoto T, et al. (2013) Efficient Utilization of Plant Resources by Alkaline Extraction. Altern Integ Med 2: 133. doi: $10.4172 / 2327-5162.1000133$

Copyright: @ 2013 Sakagami H, et al. This is an open-access article distributed under the terms of the Creative Commons Attribution License, which permits unrestricted use, distribution, and reproduction in any medium, provided the original author and source are credited. 


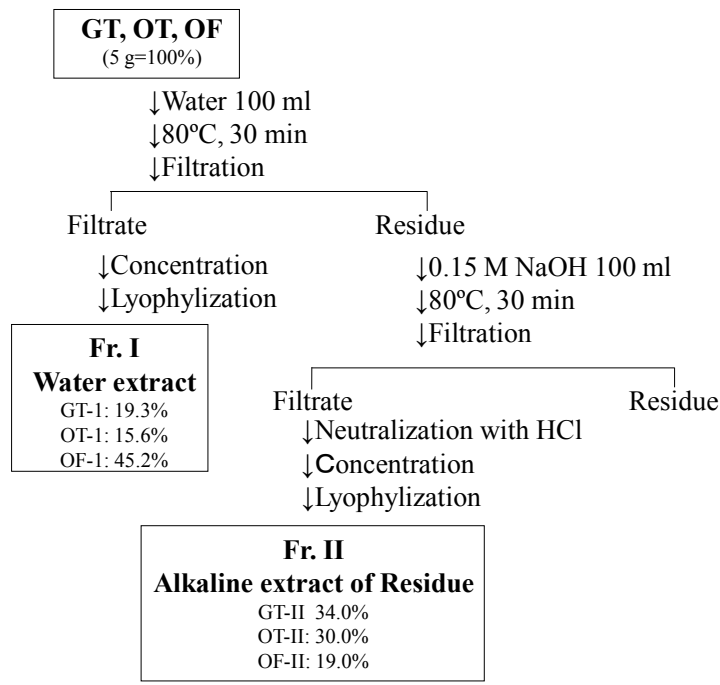

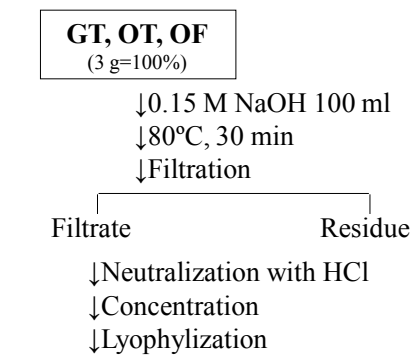

\begin{tabular}{|c|}
\hline Fr. III \\
Alkaline extract \\
GT-III: $66.1 \%$ \\
OT-III: $56.4 \%$ \\
OF-III: $65.4 \%$ \\
\hline
\end{tabular}

Figure 1: Fractional preparation of hot-water and alkaline extract from green tea leaf (GT), oolong tea leaf (OT) and orange flower (F).

of $0.15 \mathrm{M} \mathrm{NaOH}$, without hot-water extraction to give the alkaline extract (Fr. III: GT-III, OT-III, OF-III) at the yield of 66.1, 56.4 and $65.4 \%$, respectively $(47.3,35.8$ and $42.6 \%$, respectively after correction for $\mathrm{NaCl}$ present in the extracts). $\mathrm{NaCl}$, present in GT-II, GT-III, OT-II, OT-III, OF-II and OF-III, determined by atomic absorption spectrometry (HITACHI Z-2010 Polarized Zeeman Atomic Absorption Spectrophotometer, Hitachi High-Technologies Corporation, Tokyo, Japan) was $46.7,28.4,39.6,36.6,49.0$ and $34.8 \%$ of dried weight, respectively.

\section{HPLC separation of water and alkaline extracts}

HPLC was performed on a Shimadzu HPLC apparatus with a Lab Solutions Ver. 5.54 SP3 System and a model SPD-M20A Diode

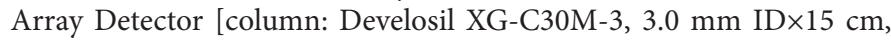
Nomura Chemical Co., Ltd.; mobile phase: 0 to $5 \mathrm{~min}, 5 \% \mathrm{CH}_{3} \mathrm{CN}$ in $0.1 \%$ trifluoroacetic acid (TFA), 5 to $20 \mathrm{~min}$, linear gradient of $5-35 \%$ $\mathrm{CH}_{3} \mathrm{CN}$ in $0.1 \%$ TFA, 20 to $25 \mathrm{~min}, 35 \% \mathrm{CH}_{3} \mathrm{CN}$ in $0.1 \%$ TFA; flow rate: $0.75 \mathrm{ml} / \mathrm{min}$; detection: UV 210-400 $\mathrm{nm}$, max; column temperature: $40^{\circ} \mathrm{C}$ ], using gallic acid, EGC, EGCg, ECg, caffeine and hesperidin as standards. Five $\mu \mathrm{l}$ of $4 \mathrm{mg} / \mathrm{ml}$ each sample was injected to HPLC.

\section{Assay for anti-HIV activity}

Human T-cell leukemia virus I (HTLV-I)-bearing CD4-positive human T-cell line, MT-4, was cultured in RPMI-1640 medium supplemented with $10 \%$ FBS and infected with HIV-1IIIB at a multiplicity of infection of 0.01 . HIV- and mock-infected MT-4 cells $\left(3 \times 10^{4}\right.$ cells/96-microwell) were incubated for 5 days with different concentrations of samples and the relative viable cell number was determined by MTT assay. The concentration that reduced the viable cell number of the uninfected cells by $50 \%\left(\mathrm{CC}_{50}\right)$ and the concentration that increased the viable cell number of the HIV-infected cells to the $50 \%$ that of control (mock-infected, untreated) cells $\left(\mathrm{EC}_{50}\right)$ were determined from the dose-response curve with mock-infected and HIV-infected cells, respectively. The anti-HIV activity was evaluated by the selectivity index (SI), which was calculated using the following equation: $\mathrm{SI}=\mathrm{CC}_{50} / \mathrm{EC}_{50}$ [5].

\section{Assay of anti-UV activity}

Human oral squamous cell carcinoma HSC-2 cells (Riken Cell
Bank, Tukuba, Japan) were inoculated into 96-microwell plates $\left(3 \times 10^{3}\right.$ cells/well, $0.1 \mathrm{ml} /$ well $)$ and incubated for 48 hours to allow cell attachment. The culture supernatant was replaced with $100 \mu \mathrm{l}$ phosphate-buffered saline without calcium and magnesium [PBS(-)] that contained different concentrations of samples in triplicate, placed at $21 \mathrm{~cm}$ distance from a UV lamp (wavelength: $253.7 \mathrm{~nm}$ ) and exposed to UV irradiation $\left(6 \mathrm{~J} / \mathrm{m}^{2} / \mathrm{min}\right)$ for 1 minute. The cells were then incubated for a further 48 hours in DMEM containing 10\% FBS to determine the relative viable cell number by the MTT assay. From the dose-response curve, the $\mathrm{CC}_{50}$ and the concentration that increased the viability of UV-irradiated cells up to $50 \%$ that of control cells $\left(\mathrm{EC}_{50}\right)$ was determined. The SI was determined using the following equation: $\mathrm{SI}=\mathrm{CC}_{50} / \mathrm{EC}_{50}[6,7]$.

\section{Assay for antibacterial activity}

Porphyromonas gingivalis 381 (ATCC33277) $\left(1 \times 10^{6} \mathrm{cfu} / \mathrm{ml}\right)$ was incubated for 24 hours at $37^{\circ} \mathrm{C}$ in Gifu Anaerobic Medium (GAM) containing containing serially diluted samples, $5 \mu \mathrm{g} / \mathrm{ml} \mathrm{hemin} \mathrm{and} 1 \mu \mathrm{g} /$ $\mathrm{ml}$ menadione under anaerobic conditions with mixed gas of nitrogen (83\%), hydrogen (7\%) and $\mathrm{CO}_{2}(10 \%)$, and then the absorbance at 595 $\mathrm{nm}$ of the bacterial suspension was measured [8]. From the doseresponse curve, the concentration that reduced the bacterial growth by $50 \%\left(\mathrm{IC}_{50}\right)$ was determined.

\section{Measurement of CYP3A4 activity}

CYP3A4 activity was measured by $\beta$-hydroxylation of testosterone using human recombinant CYP3A4 $[9,10]$. The reaction mixture, containing $200 \mathrm{mM}$ potassium phosphate buffer ( $\mathrm{pH}$ 7.4), NADPH regenerating system (1.3 mM NADPH, $1.3 \mathrm{mM}$ glucose-6-phosphate, $0.2 \mathrm{U} / \mathrm{ml}$ glucose-6-phosphate dehydrogenase, and $3.3 \mathrm{mM} \mathrm{MgCl}_{2}$ ) along with $0,10,30,100,300,600$ and $1000 \mu \mathrm{g} / \mathrm{mL}$ of the test samples or vehicle in triplicate and the human recombinant CYP3A4 (16.5 pmol/ $\mathrm{ml}$ ), was preincubated at $37^{\circ} \mathrm{C}$ for $5 \mathrm{~min}$. The reaction was started by the addition of $300 \mu \mathrm{M}$ testosterone substrates. The final volume of the reaction mixture was $250 \mu \mathrm{l}$ with a final DMSO concentration of $0.5 \%$. The reaction was stopped by the addition of $500 \mu$ lethyl acetate after 15 min. After centrifugation (15,000 g, $5 \mathrm{~min}$ ), $400 \mu \mathrm{l}$ of supernatant was collected, dried, and resuspended in $100 \mu$ l of methanol. Analyses of the metabolites were performed by HPLC (JASCO PU2089, AS2057, 
A
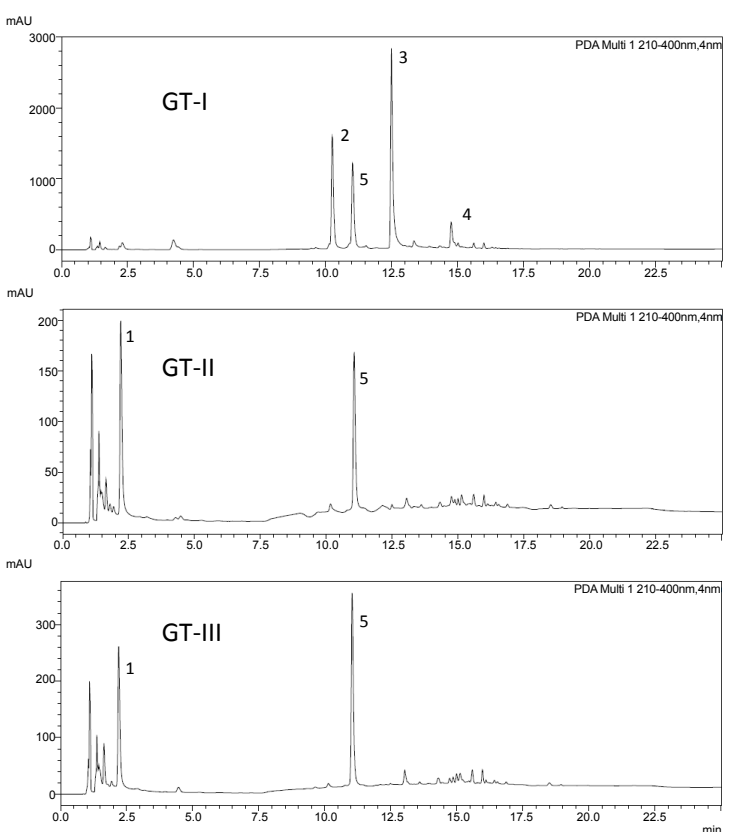
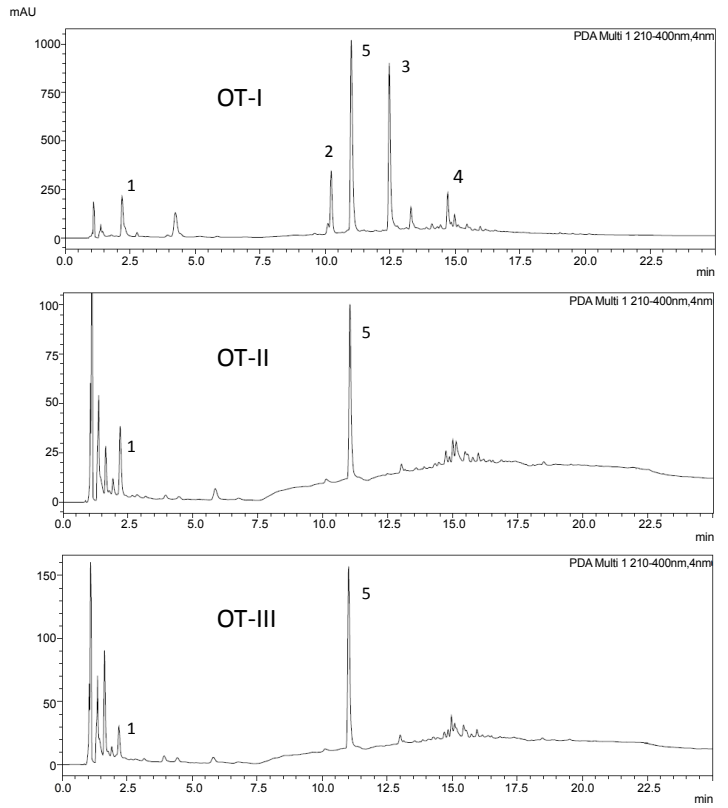

C
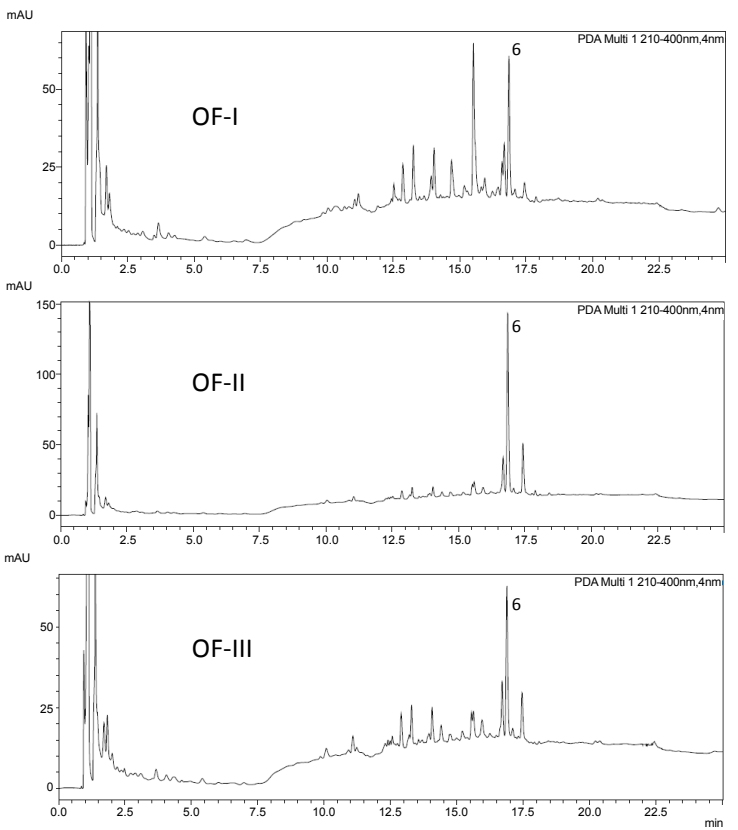

Figure 2: HPLC separation of hot-water and alkaline extracts from green tea leaf (GT), oolong tea leaf (OT) and orange flower (OF). S Standard: 1, gallic acid; 2, EGC; 3, EGCg; 4, ECg; 5, caffeine; 6, hesperidin.

UV2075 ChromNAV) equipped with TSKgel ODS-120A, $4.6 \mathrm{~mm} \mathrm{ID \times 25}$ $\mathrm{cm}, 5 \mu \mathrm{m}$ column (TOSOH, Tokyo, Japan). The mobile phase consisted of $70 \%$ methanol and $30 \%$ water. The metabolites were separated using an isocratic method at a flow rate of $1.0 \mathrm{ml} / \mathrm{min}$. Quantification of the metabolites was performed by comparing the HPLC peak area at $254 \mathrm{~nm}$ to that of $11 \alpha$-progesterone, the internal standard. The retention times for $6 \beta$-hydroxytestosterone and 11 $\alpha$-progesterone were about 4.3 and $6.0 \mathrm{~min}$, respectively. From the dose-response curve, the concentration 
Citation: Sakagami H, Ohkoshi E, Amano S, Satoh K, Kanamoto T, et al. (2013) Efficient Utilization of Plant Resources by Alkaline Extraction. Altern Integ Med 2: 133. doi:10.4172/2327-5162.1000133

Page 4 of 7

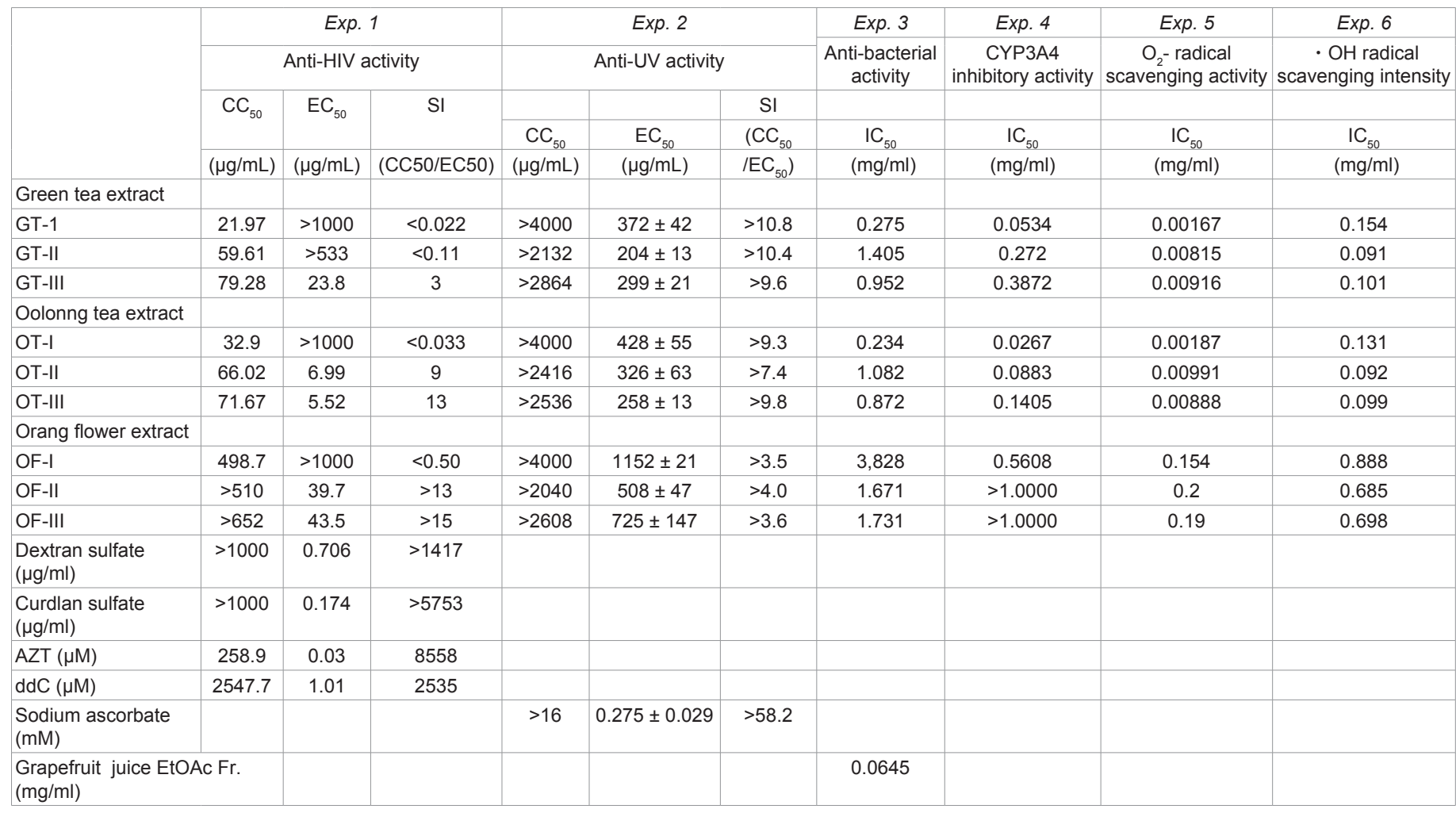

All values in alkaline extracts were corrected for $\mathrm{NaCl}$ present in the extracts.

Table 1: Biological activities of hot water and alkaline extracts of three plant materials.
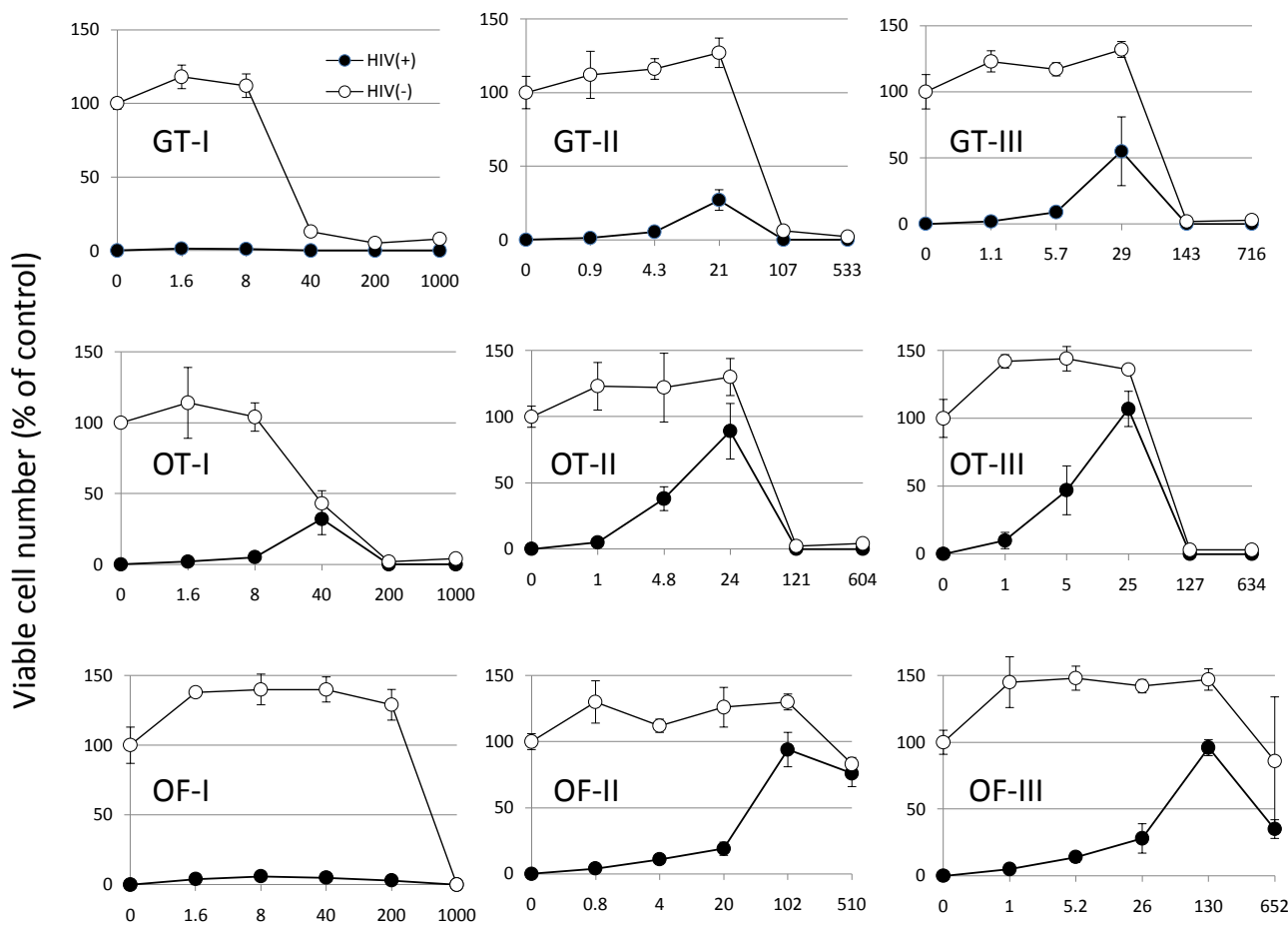

Concentration $(\mu \mathrm{g} / \mathrm{ml})$

Figure 3: Anti-HIV activity of water and alkaline extracts. HIV-1 $1_{I 1 \mathrm{~B}}$-infected $(\mathrm{HIV}+)(\bullet)$ and mock-infected $(\mathrm{HIV}-)(\circ)$ MT-4 cells were incubated for 5 days with the indicated concentrations of each sample, and the viable cell number was determined by the MTT assay and expressed as a percentage that of the control. Data represent the mean \pm S.D. from triplicate assays. $\mathrm{NaCl}$ present in the extracts was corrected. 
that inhibited the CYP3A4 activity by $50 \%\left(\mathrm{IC}_{50}\right)$ was determined.

\section{Radical-scavenging activity}

The free radical intensity was determined at $25^{\circ} \mathrm{C}$, using electronspin resonance (ESR) spectroscopy (JEOL JES REIX, X-band, $100 \mathrm{kHz}$ modulation frequency; JEOL Ltd., Tokyo, Japan) [11]. The instrument settings were: centre field, $335.5 \pm 5.0 \mathrm{mT}$; microwave power, $16 \mathrm{~mW}$; modulation amplitude, $0.1 \mathrm{mT}$ : gain, 630; time constant, $0.03 \mathrm{~s}$ and scanning time, 2 minutes. For the determination of the superoxide anion (in the form of DMPO-OOH), produced by the HX-XOD reaction (total volume: $200 \mu \mathrm{l}$ ) [2 $\mathrm{mM}$ HX in $0.1 \mathrm{M}$ phosphate buffer (PB) $(\mathrm{pH}$ 7.4) $50 \mu \mathrm{l}, 1 \mathrm{mM}$ DETAPAC $10 \mu \mathrm{l}, 10 \%$ DMPO $30 \mu \mathrm{l}$, test sample (in PB) $40 \mu \mathrm{l}, \mathrm{PB} 40 \mu \mathrm{l}, \mathrm{XOD}(0.5 \mathrm{U} / \mathrm{ml}$ in PB) $30 \mu \mathrm{l}]$, the time constant was changed to $0.03 \mathrm{~s}$ [11]. For the determination of the hydroxyl radical (in the form of DMPO-OH), produced by the Fenton reaction $(200 \mu \mathrm{l})[1$ $\mathrm{mM} \mathrm{FeSO}_{4}$ (containing 0.2 mM DETAPAC) $50 \mu \mathrm{l}, 0.1 \mathrm{M} \mathrm{PB}$ (pH 7.4) 50 $\mu \mathrm{l}, 92 \mathrm{mM}$ DMPO $20 \mu \mathrm{l}$, test sample (in $\mathrm{H} 2 \mathrm{O}$ ) $50 \mu \mathrm{l}, 1 \mathrm{mM} \mathrm{H}_{2} \mathrm{O}_{2}, 30 \mu \mathrm{l}$, the gain was changed to 160 [11]. The concentration that reduced the radical intensity of DMPO-OOH and DMPO-OH by $50 \%\left(\mathrm{IC}_{50}\right)$ was determined by the dose-response curve of triplicate samples.

\section{Statistical treatment}

Experimental values are expressed as the mean \pm standard deviation (SD). Statistical analysis was performed by using Student's $t$-test. A $p$-value $<0.01$ or $<0.05$ was considered to be significant.

\section{Results}

\section{HPLC separation of the hot-water and alkaline extracts}

Major components of GT-I were identified as EGC, EGCg, ECg and caffeine (Figure 2A). On the other hand, major components of GTII and GT-III were identified as gallic acid and caffeine, while EGC, EGCg and ECg disappeared. Elevated background peaks (retention time: 7.5 25 min) suggests the accumulation of numerous degradation products.

Major products of OT-I were gallic acid, EGC, EGCg, ECg and caffeine (Figure 2B), whereas major components of OT-II and OT-III were gallic acid and caffeine, and many peaks of degradation products. Major peaks of OF-I, OF-II and OF-III were hesperidin and many degradation products (Figure 2C).

\section{Anti-HIV activity}

All three water extracts prepared from green tea leaf, oolong tea leaf and orange flower (GT-I, OT-I, OF-I) showed no anti-HIV activity ( $\mathrm{SI}=<0.022,<0.033$ and $<0.50$, respectively) (Exp. I, Table 1) (Figure 3). Alkaline extract prepared from the residue of water extraction (GTII, OT-II, OF-II) showed slightly higher anti-HIV activity $(\mathrm{SI}=<0.11$, 9 and $>13$, respectively). Total alkaline extract (Fr. III) (GT-III, OTIII, OF-III) showed the highest anti-HIV activity ( $\mathrm{SI}=3,13$ and $>15$, respectively), although their SIs were 100 - to 600 -fold lower than that of popular anti-HIV agents (dextran sulfate, curdlan sulfate, AZT, ddT (SI=>1417, $>5753,8558$ and 2535, respectively) (Table 1). Alkaline extracts of orange flower (OF-II, OF-III) $(\mathrm{SI}=>13,>15)$ showed the highest anti-HIV activity, followed by those of oolong tea leaf (OT-II, OT-III) (SI=9, 13), and green tea leaf (GT-III) $(\mathrm{SI}=3)$. The lower activity of green tea and oolong tea leaves may be due to interfering action of cytotoxic substances.

\section{Anti-UV activity}

We recently reported that UV irradiation induced non-apoptotic cell death without induction of internucleosomal DNA fragmentation in HSC-2 cells [6]. UV irradiation (6 J/ $/ \mathrm{m}^{2} / \mathrm{min}, 1$ minute) significantly reduced the viable cell number after 48 hours' incubation. Addition of tea extracts during the UV irradiation protected the cells from UV-induced cell injury. Green tea leaf extracts showed the highest anti-UV activity, regardless of water extraction (GT-I) (SI=>10.8) or alkaline extraction (GT-II, GT-III) (SI=>10.4, >9.6), although its antiUV activity was approximately 5-times lower than sodium ascorbate $(\mathrm{SI}=>58.2)$ (Exp. 2 in Table 1). Oolong tea leaf extracts showed slightly lower anti-UV activity, regardless of water extraction (OT-I) $(\mathrm{SI}=>9.3)$ or alkaline extraction (OT-II, OT-III) (SI=>7.4, >9.4). Orange flower

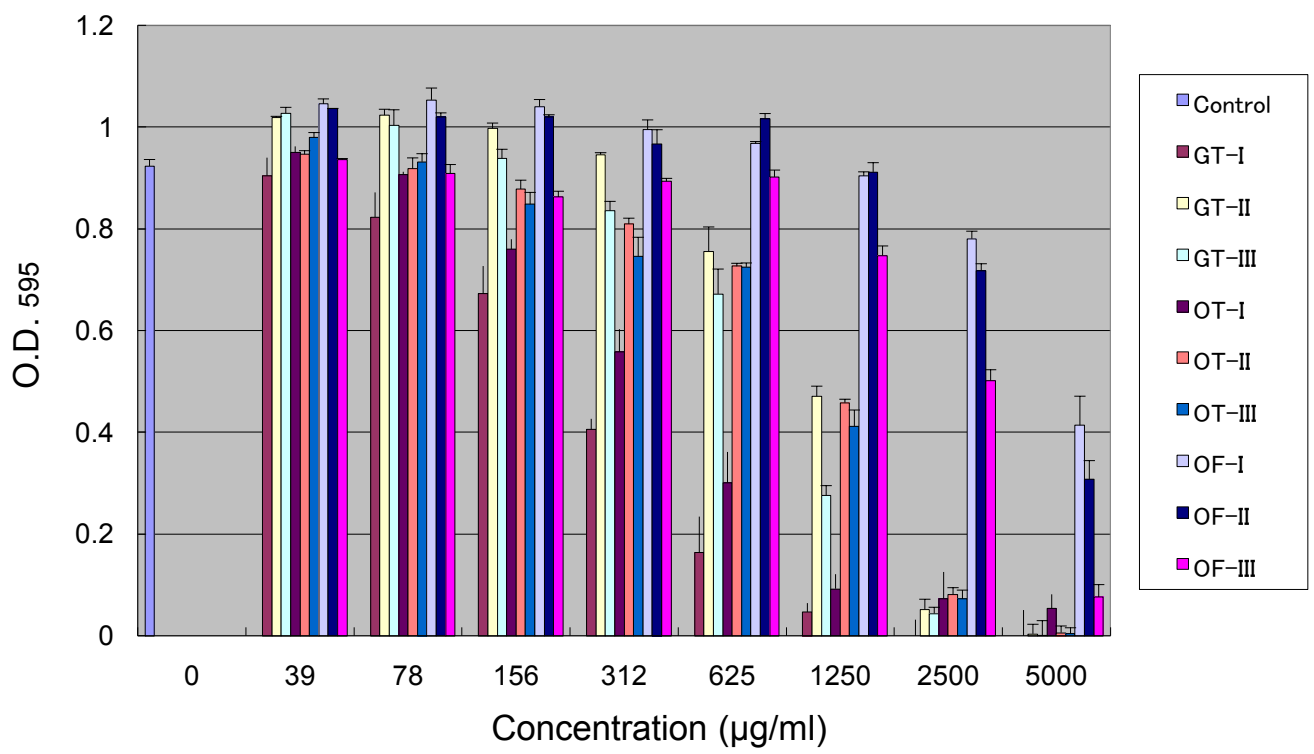

Figure 4: Antibacterial activity of GT, OT and OF extracts. Each value represents the mean \pm S.D. of triplicate assays. ${ }^{*} p<0.01$ compared with control. NaCl present in the extracts was not corrected 

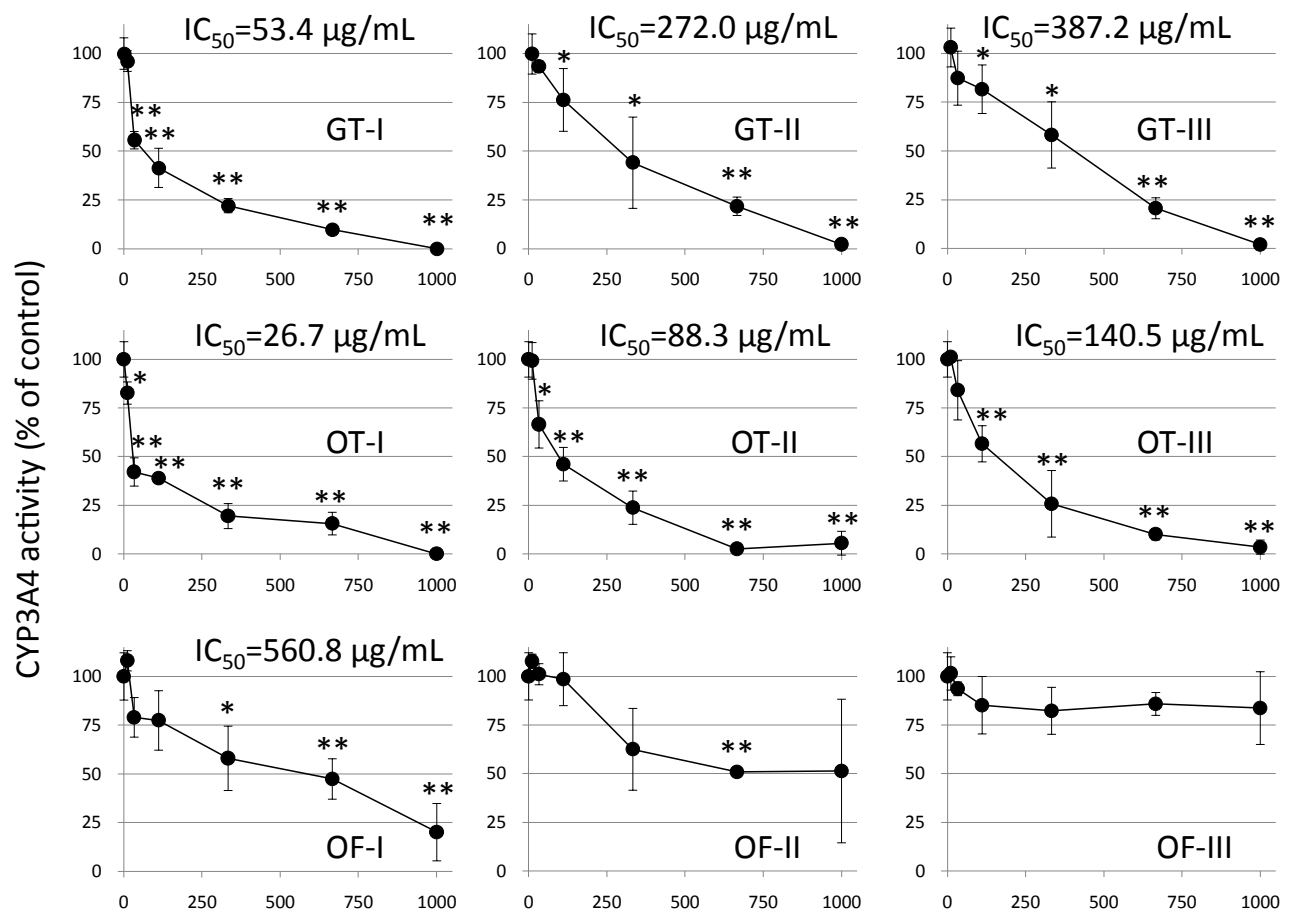

Concentration $(\mu \mathrm{g} / \mathrm{ml})$

Figure 5: Cytochrome P450 enzyme (CYP)3A4 inhibitory activity of GT, OT and OF extracts. Each value represents the mean \pm S.D. of triplicate assays. ${ }^{* *} p<0.01,{ }^{*} p<0.05$ relative to the control $(0 \%) . \mathrm{NaCl}$ present in the extracts was corrected

extracts showed the least anti-UV activity, regardless of water extraction $(\mathrm{OF}-\mathrm{I})(\mathrm{SI}=>3.5)$ or alkaline extraction $(\mathrm{SI}=>4.0,>3.6)$.

\section{Antibacterial activity}

OT-I showed the highest anti-bacterial activity against P. gingivalis $381\left(\mathrm{IC}_{50}=0.234 \mathrm{mg} / \mathrm{ml}\right.$, determined after correction of $\mathrm{NaCl}$ present in the extracts), followed by GT-I $(0.275 \mathrm{mg} / \mathrm{ml})$, OT-III $(0.872 \mathrm{mg} /$ $\mathrm{ml})$, GT-III $(0.952 \mathrm{mg} / \mathrm{ml})$, OT-II $(1.082 \mathrm{mg} / \mathrm{ml})$, GT-II $(1.405 \mathrm{mg} / \mathrm{ml})$, OF-II $(1.671 \mathrm{mg} / \mathrm{ml})$, OF-III $(1.731 \mathrm{mg} / \mathrm{ml})$ and OF-I $(3.828 \mathrm{mg} / \mathrm{ml})$ (Figure 4, Exp. 3 in Table 1). Water extracts of GT and OT were 4 to 5 - times more potent than alkaline extracts. OF extracts were much less potent. All extracts did not show any hormetic stimulation (known as growth stimulation at lower concentration ranges [12]), in contrast to alkaline extract of the leaves of Sasa senanensis Rehder (SE) [8].

\section{CYP3A4 inhibitory activity}

Water extracts (GT-I, OT-I, OF-I) inhibited CYP3A4 $\left(\mathrm{IC}_{50}=53.4\right.$, 26.7 and $560.8 \mu \mathrm{g} / \mathrm{ml}$, respectively) more potently than alkaline extracts (GT-II, GT-III=272.0, $387.2 \mu \mathrm{g} / \mathrm{ml}$; OT-II, OT-III=88.3, $140.5 \mu \mathrm{g} /$ $\mathrm{ml}$; OF-II. OF-III $=>1000,>1000 \mu \mathrm{g} / \mathrm{ml}$ ) (Figure 3; Exp. 4, Table 1). Grapefruit juice is known to inhibit the CYP3A4 activity [13]. EtOAc extractable fraction of grapefruit juice inhibited CYP3A4 activity to comparable extent with GT-I $\left(\mathrm{IC}_{50}=64.5 \mu \mathrm{g} / \mathrm{ml}\right)$. On the other hand, the CYP3A4 inhibitory activity of alkaline extracts were one order lower than that of the EtOAc extractable fraction of grapefruit juice (Exp. 4, Table 1).

\section{Radical-scavenging activity}

Water extract of green tea leaf (GT-I) most potently scavenged the superoxide anion (detected as DMPO-OOH), generated by HX and
XOD reaction $\left(\mathrm{IC}_{50}=0.00167 \mathrm{mg} / \mathrm{ml}\right)$ (Exp. 5, Table 1). Alkaline extract of green tea leaf (GT-II, GT-III) showed 5-time lower superoxide scavenging activity $\left(\mathrm{IC}_{50}=0.00815,0.00916 \mathrm{mg} / \mathrm{ml}\right)$. Water extract of oolong tea leaf (OT-I) showed comparable superoxide scavenging activity with GT-I, and alkaline extract of it was also 5-times less active. Orange flower extracts showed the weakest superoxide scavenging activity, regardless of water or alkaline extraction.

Water extract of green tea leaf (GT-I) scavenged the hydroxyl radical (detected as DMPO-OH), generated by the Fenton reaction $\left(\mathrm{IC}_{50}=0.154 \mathrm{mg} / \mathrm{ml}\right)$ (Exp. 6, Table 1). Alkaline extracts of green tea leaf (GT-II, GT-III) were slightly more active. Oolong tea leaf extracts showed comparable activity with green tea leaf extracts, whereas orange flower extracts were 7-times less active. However, in all of these cases, alkaline extracts were slightly more activity than water extracts.

\section{Discussion}

The present study demonstrated for the first time that alkaline extracts of green tea, oolong tea leaves and orange flower with $0.15 \mathrm{M}$ $\mathrm{NaOH}$ consistently gave much higher anti-HIV activity, as compared with water extracts. The low anti-HIV activity of water extracts (GTI and OT-I) may be due to the presence of gallic acid, EGC, EGCg and ECg, that had essentially no anti-HIV activity $(\mathrm{SI}<1)$ [5]. On the other hand, alkaline extracts (GT-II, GT-III, OT-II, OT-III) contained no detectable amount of EGC, EGCg and ECg, but higher amounts of gallic acid and numerous degradation products. Degradation products rather than gallic acid may be involved in the anti-HIV activity induction. We have recently purified the anti-UV substances (SEE-1) from the alkaline extract of Sasa senanensis Rehder, and identified it as $p$-coumaric acid derivative(s), a lignin precursor, by recycled HPLC and structural analysis with ${ }^{1} \mathrm{H}$ - NMR, ${ }^{13} \mathrm{C}-\mathrm{NMR}$, and UV absorption 
[14]. Further studies are required to identify the active principle(s) of alkaline extracts of GT, OT and OF. In contrast to higher anti-HIV activity, alkaline extracts of GT and OT showed 4 to 5-times lower antibacterial activity, suggesting that lower molecular weight polyphenols may be involved in the anti-bacterial activity induction.

The present study demonstrated that alkaline extracts (GT-II, GTIII, OT-II, OT-III, OF-II, OF-III) inhibited the CYP3A4 activity to much lesser extent than water extracts (GT-I, OT-I, OF-I) (Figure 4). Alkaline extracts thus seem likely to be safer as compared with water extracts, since the latter are expected to enhance the side-effects of CYP3A4-metabolizable drugs that are administered together.

We also found that alkaline extracts scavenged hydroxyl radical more efficiently than water extracts, whereas water extracts were more active in scavenging superoxide. Hydroxyl radical is known to be highly cytotoxic and mutagenic $[15,16]$, and therefore alkaline extract may prevent or reduce the incidence of hydroxyl radical-induced adverse effects.

We have recently found that alkaline extracts of GT, OT and OF more effectively inhibited the COX-2 activity, as compared with corresponding water extract (Fukuda, manuscript in preparation), suggesting their possible anti-inflammatory activity. Recent clinical research demonststrated that alkaline extracts of of Sasa senanensis Rehder leaf and pine cone of Pinus parviflora Sieb et. Zucc significantly improved the conditions of patients infected with lichenoid dysplasia [17] and herpes-simplex virus [18], respectively.

There was a possibility that some chemical entities in the plant might have been transformed or conversed during alkaline extraction. To test this possibility, gallic acid, EGCg, caffeine or hesperidin (insoluble material removed by filtration through $0.45 \mu \mathrm{m}$ filter $)(1 \mathrm{mg} / \mathrm{ml})$ in $50 \%$ $\mathrm{MeOH}$ was mixed with 10 volume of $0.15 \mathrm{M} \mathrm{NaOH}$, and stood at $80^{\circ} \mathrm{C}$ for $30 \mathrm{~min}$, or at room temperature for overnight, and then subjected to HPLC analysis. We observed that (i) both gallic acid and EGCg were completely degraded and disappeared, (ii) caffeine was significantly, but not completely degraded, and (iii) hesperidin was stable, with its peak height rather increased, possibly due to increasing solubility under either alkaline conditions (data not shown). This observation was apparently inconsistent from the present results that these compounds were relatively stable in the alkaline extract. Alkaline solution increases the extractability of phenolic compounds, which may reduce the acidity of the extract and then enhance the stability. Gallic acid in the alkaline extracts of green tea may be produced from the degradation of catechin gallates such as EGCg or lignin-related compounds.

\section{Conclusion}

The present study demonstrates that water extracts showed higher anti-bacterial, CYP3A4 inhibitory and superoxide scavenging activity, whereas alkaline extracts showed higher anti-HIV and hydroxyl radical scavenging activity. Both water and alkaline extracts showed comparable anti-UV activity. Considering that alkaline extraction gave twice as much as dried materials, as compared with water extraction (Figure 1), it is very useful method to effectively utilize the natural resources. Application of the present alkaline extraction to other plant species may hopefully manufacture products that enrich our daily life.

\section{Acknowledgements}

The authors thank Dr. Ikeda H, Satoen Food and Drug Laboratories, Satoen Co., Ltd. For his technical assistance.

\section{References}

1. Sakagami H, Kushida T, Oizumi T, Nakashima H, Makino T (2010) Distribution of lignin-carbohydrate complex in plant kingdom and its functionality as alternative medicine. Pharmacol Ther 128: 91-105.

2. Nanbu T, Shimada J, Kobayashi M, Hirano K, Koh T, et al. (2013) Anti-UV activity of lignin-carbohydrate complex and related compounds. In Vivo 27 : 133-139.

3. Sakagami H, Matsuta T, Yasui T, Oguchi K, Kitajima M, et al. (2012) Chapter 8 : Functional evaluation of Sasa Makino et Shibata leaf extract as group III OTC drug. In: Alternative Medicine (eds. Sakagami H) 171-200.

4. Kato T, Horie N, Matsuta T, Naoki U, Shimoyama T, et al. (2012) Anti-UV/HIV activity of Kampo medicines and constituent plant extracts. In Vivo 26: 10071013.

5. Nakashima H, Murakami T, Yamamoto N, Sakagami H, Tanuma S, et al. (1992) Inhibition of human immunodeficiency viral replication by tannins and related compounds. Antiviral Res 18: 91-103.

6. Ueki J, Shimada A, Sakagami H, Wakabayashi H (2011) Hormetic and UVprotective effects of azulene-related compounds. In Vivo 25: 41-48.

7. Kantoh K, Ono M, Nakamura Y, Nakamura Y, Hashimoto K, et al. (2010) Hormetic and anti-radiation effects of tropolone-related compounds. In Vivo 24 843-851.

8. Sakagami H, Amano S, Yasui T, Satoh K, Shioda S, et al. (2013) Biological interaction between Sasa senanensis Rehder leaf extract and toothpaste ingredients. In Vivo 27: 275-284.

9. Sakagami H, Iwamoto S, Matsuta T, Satoh K, Shimada C, et al. (2012) Comparative study of biological activity of three commercial products of Sasa senanensis Rehder leaf extract. In Vivo 26: 259-264.

10. Sakagami H, Matsuta T, Satoh K, Ohtsuki S, Shimada C, et al. (2012) Biological activity of SE-10, granulated powder of Sasa senanensis Rehder leaf extract. In Vivo 26: 411-418.

11. Sakagami H, Asano K, Satoh K, Takahashi K, Terakubo S, et al. (2006) Antistress activity of mulberry juice in mice. In Vivo 20: 499-504.

12. Calabrese EJ (2005) Paradigm lost, paradigm found: the re-emergence of hormesis as a fundamental dose response model in the toxicological sciences. Environ Pollut 138: 379-411.

13. Arayne MS, Sultana N, Bibi Z (2005) Grape fruit juice-drug interactions. Pak J Pharm Sci 18: 45-57

14. Matsuta T, Sakagami H, Sugiura T, Kitajima M, Oizumi H, et al. (2013) Structural characterization of anti-UV components from Sasa senanensis Rehder extract. In Vivo 27: 77-83.

15. Genovese T, Cuzzocrea S (2008) Role of free radicals and poly(ADP-ribose) polymerase-1 in the development of spinal cord injury: new potential therapeutic targets. Curr Med Chem 15: 477-487.

16. Varma SD, Kovtun S, Hegde KR (2011) Role of ultraviolet irradiation and oxidative stress in cataract formation-medical prevention by nutritional antioxidants and metabolic agonists. Eye Contact Lens 37: 233-245.

17. Matsuta T, Sakagami H, Tanaka S, Machino M, Tomomura M, et al. (2012) Pilot clinical study of Sasa senanensis Rehder leaf extract treatment on lichenoid dysplasia. In Vivo 26: 957-962.

18. Lopez BS, Yamamoto M, Utsumi K, Aratsu C, Sakagami H (2009) A clinical pilot study of lignin--ascorbic acid combination treatment of herpes simplex virus. In Vivo 23: 1011-1016. 